\title{
Treatment of Non-puerperal Galactorrhoea with an Ergot Alkaloid
}

\author{
P. M. LUTTERBECK, J. S. PRYOR, L. VARGA， R. WENNER
}

British Medical fournal, 1971, 3, 228-229

\section{Summary}

Three patients suffering from non-puerperal galactorrhoea over periods ranging from two months to six years were treated with an ergot alkaloid, 2-Br-alphaergocryptine (CB 154). In all three cases the galactorrhoea was terminated. The apparent prolactin antagonism exhibited by this compound is discussed.

\section{Introduction}

The occurrence of galactorrhoea unassociated with pregnancy can be seen in a variety of circumstances. These include disorders of the pituitary-for example, acromegaly-adrenal cortex, and ovary, imbibing of certain drugs-for example, phenothiazines-and surgical procedures involving the chest wall. This subject has been extensively and adequately reviewed by Sulman (1970). Despite our understanding of the physiological mechanisms resulting in galactorrhoea it often poses an intractable medical problem.

We report the successful treatment of three cases of nonpuerperal galactorrhoea with an ergot alkaloid, 2-Br-alphaergocryptine (CB 154).

\section{Case 1}

Since the birth of her only child in 1966 and after a seven-month period of breast-feeding a 27-year-old housewife had been suffering from persistent galactorrhoea. Menstruation was irregular (25-33 days) but of normal duration and severity. She first sought medical attention in March 1970 complaining of mammary pain, tenderness, and a milky discharge on manual expression of each breast. She denied the intake of any prescribed medication. Physical examination showed only the presence of bilateral galactorrhoea. The following laboratory investigations were carried out: haemoglobin; W.B.C.; E.S.R.; B.U.N.; serum $\mathrm{Na}^{+}, \mathrm{K}+, \mathrm{Ca}++$, fasting and postprandial venous glucose; P.B.I.; thyroid antibody tests; total lipids; plasma 17-hydroxycorticosteroids and response to ACTH, and urine analysis-24-hour urinary gonadotrophin, 17-ketosteroid, pregnandiol, oestriol, and oestron-oestradiol excretion. All were within normal limits. Routine skull $x$-ray pictures and tomograms of the sella turcica showed a unilateral ballooning of the sella and a double contour formation of the floor of the dorsum sellae. Radiologically this finding was considered as suggestive of a pituitary tumour. An ophthalmoscopic examination including perimetry showed nothing abnormal.

The patient menstruated normally from 4 to 11 December and was examined again on the 16th. Next day she started treatment with 1-mg capsules of CB 154 three times a day. During the first

\footnotetext{
Department of Experimental Therapeutics, Biological and Medical Research Division, Sandoz Ltd., Basle, Switzerland

P. M. LUTTERBECK, M.D., Physician

J. S. PRYOR, M.B., M.R.C.P., Physician

Department of Obstetrics and Gynaecology, Kantonsspital, Liestal, Switzerland

L. VARGA, M.D., Oberartz

R. WENNER, M.D., Professor of Obstetrics and Gynaecology
}

week of therapy she experienced slight nausea one to two hours after taking the capsules. On 23 December discharge was not expressible from the left breast and only a minimal amount was produced from the right. During the next eight days the dosage was increased to $2 \mathrm{mg}$ three times daily. The nausea became more severe, but a steady alleviation of mammary pain and tenderness was clearly discernible by the patient. The dose was raised to $3 \mathrm{mg}$ three times daily, and while her mammary symptoms completely subsided she stopped the medication after five days because of vomiting. Physical examination showed no discharge from the left breast and only a scant amount from the right. Subsequently she was maintained on $1 \mathrm{mg}$ three times a day between 7 and 20 January. She was seen on 13 and 20 January and found to have no discharge expressible from either breast. Side effects did not occur.

On 21 January the patient was switched to placebo on a singleblind basis. Three days later she was able to express milk from both breasts, and on two other occasions up to 27 January we were able to confirm this ourselves. From 28 January she was maintained on $1 \mathrm{mg}$ three times a day, and at the time of writing had remained completely asymptomatic. While on CB 154 she menstruated normally.

\section{Case 2}

This patient was a 27-year-old mother of two (born in 1965 and 1968). On 3 December 1970 an episode of acute bilateral mammary engorgement occurred accompanied by severe pain and tenderness and a profuse milky discharge on the slightest pressure. Her past history was normal, menstruation having been regular (28-30 days), lasting six days, and of moderate severity, the last period having occurred on 14 November. She denied the intake of any prescribed medication. Physical examination on 14 December showed nothing abnormal except for the above condition. Routine skull $x$-ray appearances and mammography were normal. She was started on $1 \mathrm{mg}$ capsules of CB 154 three times daily on 15 December. The dose was increased to $2 \mathrm{mg}$ three times daily on the 23rd and again raised to $3 \mathrm{mg}$ on 31 December.

The patient was re-evaluated on 6 January when firm pressure to both breasts produced a slight thick grey discharge from the right and a minimal amount from the left. She no longer complained of mammary pain, tenderness, or engorgement. Apart from slight dizziness occurring only a fev days after the start of treatment no side effects were reported.

Because of some persistently expressible residual discharge and the absence of side effects the dose was increased to $4 \mathrm{mg}$ three times daily, beginning an 7 January. This was poorly tolerated owing to severe dizziness. Consequently the dose was reduced to $8 \mathrm{mg} /$ day during the next two days but dizziness persisted and therefore no drug was taken on 10 January. The following day she experienced an episode of acute bilateral mammary engorgement associated with severe pain and tenderness. On that day and for the following two days she took $8-10 \mathrm{mg} /$ day. On the 13th she was reassessed and found to have a minimal discharge on firm pressure from the right breast, while none could be expressed from the left. Both breasts had a consistency characteristic of the puerperium. After restarting CB 154 she became free from pain and tenderness. She was maintained on $3 \mathrm{mg}$ three times daily for the next three weeks. Meanwhile examination after the first week distinctly showed that the firm consistency of the mammary tissue had subsided. A scant discharge was expressed from the right breast, but none came from the left.

Examination on 2 February confirmed the complete absence of galactorrhoea, and the patient was asymptomatic. While suffering from galactorrhoea and being maintained on CB 154 she menstruated normally. 


\section{Case 3}

A 29-year-old housewife had been suffering from bilateral galactorrhoea and mammary discomfort for the past six years since the birth of her only child. During this time she had been evaluated psychiatrically because of a hyperventilation syndrome associated with perioral and localized acral paraesthesia, muscular cramps, and occasional fainting spells. No other abnormalities were noted. Physical examination on 17 November 1970 showed nothing other than galactorrhoea. $X$-ray appearances of the sella turcica were normal.

From 19 to 28 December the patient took daily a single 3-mg capsule of CB 154 by mouth before breakfast. While she experienced slight nausea, her galactorrhoea and mammary discomfort greatly diminished, the latter disappearing entirely. Increasing the dose to $3 \mathrm{mg}$ twice daily on 29 December resulted by 1 January in regular vomiting soon after taking the drug, and it was therefore withdrawn. Physical examination on 6 January showed a milky discharge from both breasts of similar magnitude to that present before CB 154 administration.

\section{Evaluation of Results}

In Case 1 the gradual disappearance of galactorrhoea after persisting nearly five years (possibly associated with a pituitary tumour) and the recurrence after stopping CB 154 wholly justifies linking the response with the action of the drug.

In Case 2, as in the first, a gradual disappearance of galactorrhoea was noted, beginning with the first week of therapy. In this instance, however, the condition was acute and a therapeutic response was interrupted by the patient having initially to reduce and eventually withhold the drug entirely because of dizziness. The ensuing acute mammary engorgement on withdrawal and its disappearance after reinstituting CB 154 assured the observers and the patient of the drug's therapeutic effect.
The situation in Case 3 was less decisive but nevertheless suggestive. Here a therapeutic response was short-lived by the occurrence of side effects. Unfortunately, at the time a 3-mg capsule formulation was all that was available. When the more flexible dosage form of $1 \mathrm{mg}$ again becomes obtainable another therapeutic regimen will be tried.

\section{Discussion}

Management of non-puerperal galactorrhoea has centered chiefly on the use of various oral contraceptives or oestrogens (Williams, 1968). While some have claimed that oral contraceptives are therapeutically effective, others have implicated them as causative (Gregg, 1966). The clinician confronted by a patient with non-puerperal galactorrhoea, in whom a pituitary lesion is suspected (as suggested by our Case 1), believes that he is dealing with an organic abnormality which is interfering with the normal inhibitory control mechanism of prolactin secretion. On the other hand, when an aetiological factor is not evident the galactorrhoea is probably regarded as attributable to an illdefined hypothalamic dysfunction associated with an inadequate production of prolactin inhibitory factor or interference with its action (analogous to our Case 2).

A series of animal pharmacology experiments using various species in Sandoz's Laboratories suggested that CB 154 interfered specifically with pituitary prolactin (Billeter and Flückiger, 1971; Wagner et al., 1971).

\section{References}

Flückiger, E., and Wagner, H. R. (1968). Experimentia, 24, 1130.

Gregg, W. (1966). New England fournal of Medicine, 274, 1432.

Sulman, F. G. (1970). Monographs on Endocrinology: Hypothalamic Control of Lactation. Berlin, Springer.

Wagner, H. R., Billeter, E., Stütz, P., and Flückiger, E. (1971). Unpublished.

Williams, R. H. (1968). Textbook of Endocrinology, Philadelphia, Saunders, 4th edn.

\section{MEDICAL MEMORANDA}

\section{Pulmonary Tuberculosis Due to B.C.G.}

\section{J. MARKS, P. A. JENKINS, G. S. KILPATRICK, H. C. ENGBAEK, B. VERGMANN}

British Medical fournal, 1971, 3, 229-230

Cases of individuals who lack the capacity to resist mycobacteria and suffer a progressive and fatal infection when vaccinated with B.C.G. despite the organism's low virulence are rare. Mande (1968) reviewed 13 such patients but noted only 20 further cases of "metastatic" lesions due to B.C.G. He

Tuberculosis Reference Laboratory, Cardiff CF2 3UJ

J. MARKS, M.D., F.R.C.PATH., Consultant Bacteriologist

P. A. JENKINS, PH.D., Principal Scientific Officer

Welsh National School of Medịcine, Cardiff CF2 1YE

G. S. KILPATRICK, M.D., F.R.C.P.ED., Senior Lecturer in Tuberculosis and Diseases of the Chest

State Serum Institute, Copenhagen

H. C. ENGBAEK, M.D., Chief of Tuberculosis Department

B. VERGMANN, B.PHARM., Scientific Assistant considers, therefore, that susceptible people of this type represent a distinct class and not the tail end of a distribution curve of innate immunity. In the fatal cases at least other immunity defects were usually evident also.

Fatal infections with B.C.G. are generalized and the lungs are affected like other organs. Nevertheless, there appears to have been no previous record of a case of metastatic B.C.G. infection presenting as pulmonary tuberculosis. Such a case is reported here.

\section{Case History}

The patient, a girl born in 1950, developed juvenile rheumatoid arthritis in 1955 but had never been treated with corticosteroids. Vaccination with B.C.G. in 1964 was a routine measure without a subsequent tuberculin test for conversion. Her arm was uncomfortable and the lesion discharged for six weeks but no other local reaction was seen. In 1967 Crohn's disease was diagnosed and a hemicolectomy was performed; non-caseating granulomata considered typical of the condition were found on section. A further operation was necessary a year later for relieving intestinal obstruction. Urine and faeces were not cultured for mycobacteria during these illnesses.

In 1968 small lesions were found radiologically in the lower zones of both lungs (see Fig.), which had been clear in 1967. The lesions could not be traced to acute infection. A Mantoux test was negative with 100 tuberculin units and no tubercle bacilli were seen in sputum films, but the cultures proved positive. Treatment was therefore undertaken with streptomycin $1 \mathrm{~g}$ daily by intramuscular injection 